\title{
Nematode Hsp90: highly conserved but functionally diverse
}

\author{
VICTORIA GILLAN* and EILEEN DEVANEY \\ Institute of Biodiversity, Animal Health and Comparative Medicine, College of Medical, Veterinary and Life Sciences, \\ University of Glasgow, Garscube Estate, Bearsden Road, Glasgow, G61 1QH, UK
}

(Received 13 December 2013; revised 14 February 2014; accepted 14 February 2014)

\section{SUMMARY}

Nematodes are amongst the most successful and abundant organisms on the planet with approximately 30000 species described, although the actual number of species is estimated to be one million or more. Despite sharing a relatively simple and invariant body plan, there is considerable diversity within the phylum. Nematodes have evolved to colonize most ecological niches, and can be free-living or can parasitize plants or animals to the detriment of the host organism. In this review we consider the role of heat shock protein 90 (Hsp90) in the nematode life cycle. We describe studies on Hsp90 in the free-living nematode Caenorhabditis elegans and comparative work on the parasitic species Brugia pahangi, and consider whether a dependence upon Hsp90 can be exploited for the control of parasitic species.

Key words: Nematodes, Caenorhabditis elegans, Brugia pahangi, Hsp90, heat shock protein, co-chaperone.

\section{INTRODUCTION}

The majority of nematodes are free-living, playing important roles in ecosystem health and diversity, but many are important and prolific parasites. For an idea of scale, approximately half the world's population, predominantly in tropical regions, harbour a nematode infection (www.nematode.net). These worms typically cause chronic infections that contribute significantly to morbidity, but rarely kill their hosts. The most abundant parasitic species are gastrointestinal nematodes such as Ascaris lumbricoides, which infects an estimated 807 million, closely followed by Trichuris trichiura (infecting an estimated 604 million) and the hookworms (infecting approximately 576 million) (http://www.cdc.gov/parasites/). These infections are often particularly prevalent and clinically important in children. Filarial nematodes are tissue-dwelling worms that account for an additional 157 million infections and are the causative agents of river blindness (Onchocerca volvulus) and elephantiasis (Wuchereria bancrofti and Brugia spp.). In addition to their importance as human pathogens, around $10 \%$ of global crop loss is due to plant parasitic nematodes (Nicol et al. 2011), while nematode parasites of livestock cause major economic production losses to grazing ruminants. Currently, infection is controlled by the use of anthelmintic drugs. However, anthelmintic resistance, particularly in nematodes of small ruminants such as sheep and goats, is endemic in most countries (Gilleard, 2006).

* Corresponding author: Institute of Biodiversity, Animal Health and Comparative Medicine, College of Medical, Veterinary and Life Sciences, University of Glasgow, Garscube Estate, Bearsden Road, Glasgow, G61 1QH, UK. E-mail: victoria.gillan@glasgow.ac.uk
Given that the same anthelmintic drugs are used in mass administration campaigns to treat human nematode infection, there is concern over the possible development of resistance in human nematodes (Vercruysse et al. 2012), underscoring the need for the development of new drugs to control these pathogens (Geary et al. 2010). In this review, we focus on the role of Hsp90 in both free-living and parasitic nematodes, specifically Caenorhabditis elegans and Brugia spp. (life cycles of which are outlined in Fig. 1) and discuss the potential of Hsp90 as a drug target for the treatment of some helminth infections.

\section{NEMATODE GENOMES}

Analysis of nematode phylogeny based on the small subunit ribosomal DNA sequences divided the phylum into five clades: Dorylaimia (Clade I), Enoplia (Clade II), Spurina (Clade III), Tylenchina (Clade IV) and Rhabditina (Clade V), each containing parasitic species (Blaxter et al. 1998). The freeliving model organism C. elegans belongs to clade $\mathrm{V}$, along with many important parasitic species of humans and animals, while filarial nematodes and Ascaris belong to clade III. C. elegans is commonly used to study the fundamental principles of biology and for understanding mechanisms of human disease, as well as acting as a model for parasitic nematodes (Kirienko et al. 2010; Hashmi et al. 2013; Li and Le, 2013). In 1998, the sequencing of the $C$. elegans genome heralded a new era of whole-organism research, and inspired other nematode genome sequencing projects. Draft genome sequences are now available for a range of parasitic species including Brugia malayi (Ghedin et al. 2007), Ascaris suum (Jex et al. 2011), Trichinella spiralis 

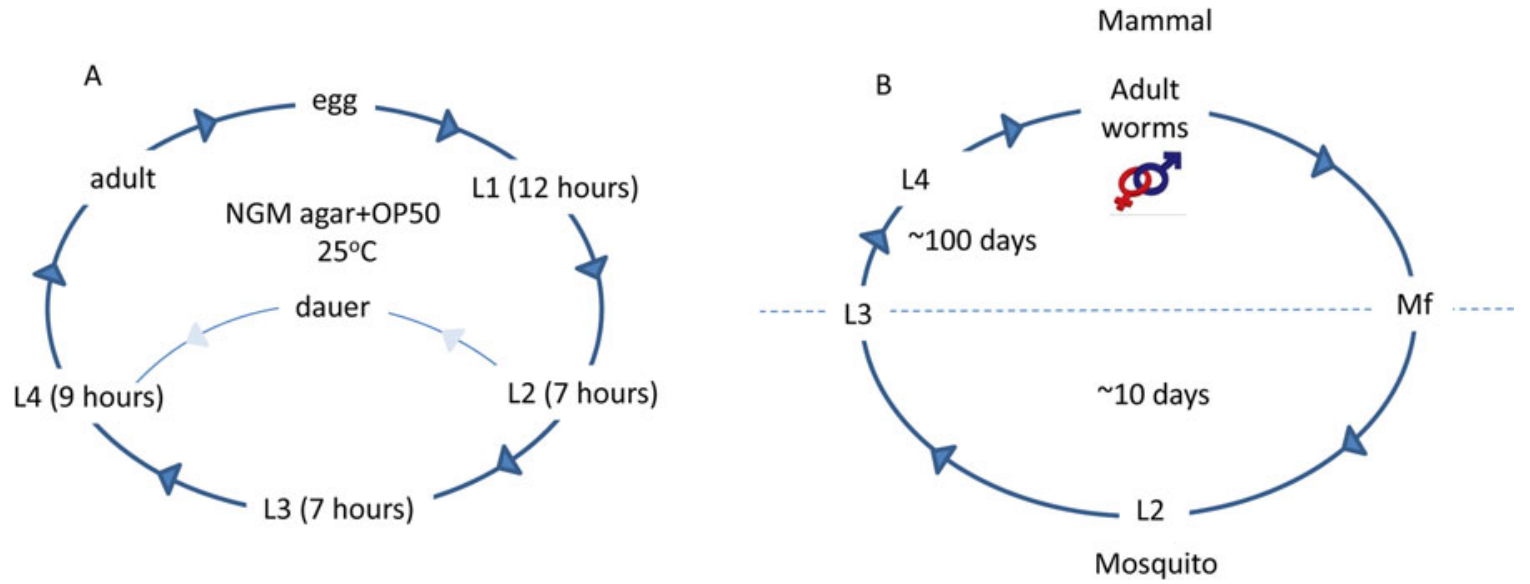

Fig. 1. Life cycle of the free-living nematode C. elegans and the parasitic lymphatic filarial nematodes. The normal hermaphroditic life cycle of $C$. elegans (A) takes approximately 3 days. Eggs are fertilized within the adult and after laying, hatch and worms proceed through four larval stages, each of which ends in a moult. Each adult will lay approximately 300 eggs and live for approximately 2 weeks. Under adverse conditions (i.e. lack of food, unfavourable temperatures or overcrowding), C. elegans can enter an alternative pathway called 'dauer'. In this state, worms can remain dormant for 3 months and can re-enter the life cycle when the environment becomes favourable. All the lymphatic filarial nematodes share an invariant life cycle (B). The full developmental cycle takes place in the mosquito (the intermediate host) or the human (the definitive host). Infection of the definitive host is initiated by the bite of a mosquito harbouring the infective L3. The L3 enters the body via the puncture site and migrates to the lymphatic system of the mammalian host. L3 moult through L4 to become sexually mature adult male and female worms, which have a lifespan of approximately 8 years. After sexual reproduction the female worms release microfilariae (Mf, first stage larvae), which migrate to the bloodstream and are available for ingestion by a mosquito taking a blood meal.

Development from Mf to the L3 stage within the mosquito occurs in the thoracic muscles and is a temperaturedependent process (optimal $28{ }^{\circ} \mathrm{C}$ and $80 \%$ humidity). Mature L3 migrate to the feeding structures in the head of the mosquito, which facilitates their transmission to the definitive host. It should be noted that other species of parasitic nematode do not require an arthropod intermediate host and have 'free-living' stages, where they are present in the environment in an infective form. The schematic presented above refers to lymphatic filarial parasites only.

(Mitreva et al. 2011), Dirofilaria immitis (Godel et al. 2012), Haemonchus contortus (Laing et al. 2013; Schwarz et al. 2013), Loa loa (Desjardins et al. 2013), Necator americanus (Tang et al. 2014) and the plant parasitic nematodes Melodoigyne incognita (Abad et al. 2008), Meloidogyne hapla (Opperman et al. 2008), as well as the necromenic species Pristionchus pacificus (Dieterich et al. 2008; Rae et al. 2008) and additional Caenorhabditis species (Stein et al. 2003). In addition, the 50 helminth genomes project coordinated by the Wellcome Trust Sanger Institute aims to provide draft genomes for 50 helminths, including many important parasitic nematodes (see www.sanger.ac.uk/research/initiatives/ globalhealth/research/helminthgenomes/).

Furthermore, there are databases of expressed sequence tags (ESTs), which have proved to be very useful in establishing a catalogue of the mRNA transcripts expressed in various species and in different life cycle stages. Access to ESTs can be found in various online databases, the most extensive of which is NEMBASE4 (http://www.nematodes. org/nembase4/) which reports on over 223000 nematode genes across $>60$ species. Nematode transcriptomics (RNA sequencing) is set to blossom in the coming years with the advent of next generation sequencing with high throughput at significantly lower cost, thus enabling the production of large datasets. The comparative analysis of multiple nematode genomes should facilitate the identification of candidate genes of interest and hopefully lead to new drug targets for many nematode pathogens.

\section{HSP90 IN NEMATODES}

Hsp90 is a highly conserved molecule across all species. For example, Hsp90 from B. malayi and Brugia pahangi are $99.9 \%$ identical. Hsp90 from humans and Brugia spp. share $77 \%$ identity, while Hsp90 from C. elegans and Brugia spp. are 84\% identical. Despite this level of conservation, the function of Hsp90 seems to vary between different nematode species, as it does between normal and malignant mammalian cells (Kamal et al. 2003). The first indication that some nematodes may possess an atypical Hsp90 came from a study that demonstrated that $C$. elegans Hsp90 (DAF-21) was unable to bind to geldanamycin (GA), the prototype Hsp90 inhibitor (David et al. 2003). DAF-21 is clearly required in $C$. elegans, as demonstrated by the arrested phenotype of a loss of function mutant (Birnby et al.2000). However, attempts to chemically inhibit DAF-21 by growth of the nematode on plates containing high levels of GA or by feeding worms on cultures of Streptomyces hygroscopicus (the actinomycete which synthesizes GA), produced no obvious phenotype 
Free living

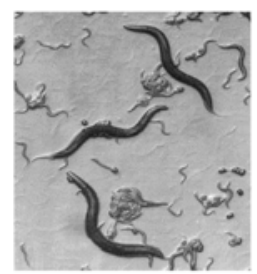

No GA binding

C. elegans (Clade V)

C. briggsae (Clade V)

$P$. pacificus (Clade V)

O. tipulae (Clade V)

$P$. redivivus (Clade IV)
Parasitic but with

free living larvae

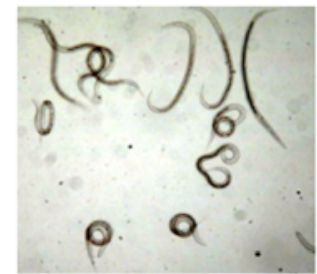

No GA binding

H. contortus (Clade V)

$T$. circumcincta (Clade V)

H. polygyrus (Clade V)

N. brasilensis (Clade V)

G. pallida (Clade IV)

G. rostochiensis (Clade IV)
Parasitic with eggs

Obligate parasites

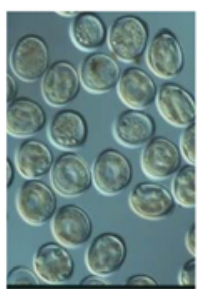

GA binding

T. cati (Clade III)

$P$. equorum (Clade III)

A. suum (Clade III)

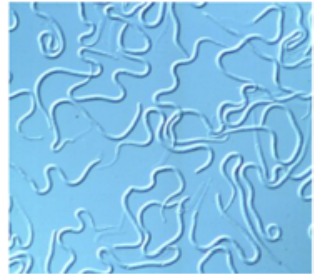

GA binding

B. pahangi (Clade III)

O. ochengi (Clade III)

D. immitis (Clade III)

A. viteae (Clade III)

T. spiralis (Clade I)

Fig. 2. Outline of nematode species and GA-binding properties. Extracts of nematodes were incubated with GA beads and pull-downs analysed by SDS-PAGE and immune-blotting. Details in Him et al. (2009).

(David et al. 2003). A subsequent survey of Hsp90 in 24 different nematode species demonstrated that $C$. elegans DAF-21 was not unique in this respect (Him et al. 2009). Using extracts of a variety of free-living and parasitic nematodes, it was shown that the ability to bind GA was associated with the life history of a particular species. Nematodes that are obligate parasites or those that live in the environment enclosed within an egg were able to bind GA; in contrast, free-living species and those with free-living larval stages did not bind GA (summarized in Fig. 2). This analysis is consistent with the adaptive evolution hypothesis proposed by David et al. in their original paper. Streptomyces hygroscopicus is a soildwelling species and thus nematodes with free-living stages in the environment may be exposed to GA or similar inhibitors during their life cycle, driving the evolution of a GA-resistant form of Hsp90. To further test this hypothesis, the amino acid sequences of Hsp90 from 15 species of nematodes were compared to determine if any of the GA-resistant strains showed evidence of adaptive Darwinian evolution. Although there was evidence of rapid diversifying evolution of $h s p 90$ along three separate nematode lineages, no evidence was found for amino acid changes that correlated with a change in GAbinding (Him et al. 2009). Thus the rapid evolution of the $h s p 90$ gene is presumably associated with some other important function, given its multifaceted role within the cell.

Studies using chimeric Hsp90 molecules demonstrated that the inability of $C$. elegans DAF-21 to bind GA was associated with the $\mathrm{N}$-terminal region (David et al. 2003). GA is a natural product of $S$. hygroscopicus and studies on this organism and on other microbes that produce Hsp90 inhibitors, have cast some light upon the adaptive mechanisms by which these organisms avoid self-toxicity. A combination of elegant structural and mutational studies in S. hygroscopicus (Millson et al. 2011) and in the fungus, Humicola fuscoatra, which synthesizes the Hsp90 inhibitor Radicicol, demonstrated the importance of naturally occurring amino acid substitutions in the N-terminal domain of Hsp90, which alter the binding of the appropriate drug. For $H$. fuscoatra, a single leucine to isoleucine substitution (L34I) within the N-terminal binding pocket of Hsp90 significantly altered the binding of Radicicol, while retaining the ability to bind GA and ATP and its chaperone activity (Prodromou et al. 2009). These studies raise the question of whether such evolutionary pressures can result in similar mutations within $h s p 90$ of higher organisms. Despite its widespread use as a model organism, our understanding of the ecology of $C$. elegans in the wild remains patchy: does $C$. elegans live in the same ecological niche as inhibitor-producing microbes in nature? A recent study surveyed the bioavailability of over 1000 drug-like molecules in C. elegans and demonstrated that many molecules fail to accumulate in the worm and thus have no apparent activity (Burns et al.2010), further suggesting that protection against toxins could be a credible selection pressure. However, while this phenomenon may contribute to the lack of activity of Hsp90 inhibitors on C.elegans, it does not explain the inability of DAF-21 to bind to Hsp90 inhibitors in soluble extracts.

FUNCTIONALSTUDIES ON HSP90 IN C. ELEGANS

Hsp90 has been well characterized in yeast and cultured mammalian cell lines, as an ATP-dependent, ubiquitous, molecular chaperone, which interacts with multiple 'client' proteins; these are proteins which require the activity of $\mathrm{Hsp} 90$ for folding or stability. However, much less is known about the cellular function of Hsp90 in the complete metazoan. 
Inevitably, much of our understanding of the role of Hsp90 in nematodes comes from work on C. elegans. This free-living nematode is easily maintained in the laboratory setting, unlike parasitic species, which often have complex life cycles involving intermediate and definitive hosts and/or stages that develop in the environment (summarized in Fig. 1). The life cycle of $C$. elegans takes only 3 days and, additionally, a range of powerful molecular techniques such as RNA interference (RNAi), mutagenesis and transgenesis, can be employed in C. elegans, whereas the application of such methods to most parasitic nematodes is in its infancy.

Mammals and yeast contain two isoforms of Hsp90 present in the cytosol, while in C. elegans there is a single $h s p 90$ orthologue, known as daf-21, located on chromosome V. Worms with a loss of function mutation in $d a f-21$ arrest at the L2-L3 stage (Birnby et al. 2000) confirming the requirement for wild type DAF-21 in life cycle progression in C. elegans. Early studies demonstrated that C. elegans underwent a classical heat shock response following exposure to elevated temperature, with the induction of a number of genes, particularly those encoding small Hsps (Candido et al. 1989; Jones et al. 1989). The expression of most Hsps in response to elevated temperature is regulated by heat shock factor (HSF1), a transcription factor that binds to conserved heat shock elements in the upstream region of Hsp genes (Wu, 1995). However, in C. elegans knock-down of $h s f-1$ by RNAi had minimal effect upon the levels of DAF-21 in nematodes exposed to heat shock, while significantly decreasing the expression of the small Hsp, Hsp-16 (Walker et al. 2003). These data suggest that $d a f-21$ expression may be regulated by factors other than the classic HSF-1. Interestingly, previous studies had shown that $d a f-21$ was up-regulated 15 -fold in dauer larvae, an alternative developmental stage that $C$. elegans can enter upon encountering unfavourable conditions, such as overcrowding or lack of food. Dauer larvae are stress-resistant and long-lived. Entry into, and recovery from, the dauer stage is regulated by levels of a pheromone produced by the worms (Golden and Riddle, 1982). When worms were stimulated to exit the dauer stage, levels of daf-21 mRNA declined rapidly (Dalley and Golomb, 1992). Similar findings were reported by Jones et al. (2001) who showed that the expression of $d a f-21$ was up-regulated in the dauer stage compared with mixed life cycle stages, but that this was not the case for $h s p-70$ (Jones et al. 2001). However, comparative proteomic analysis of $C$. elegans mixed life cycle stages and dauer larvae showed no overexpression of DAF-21 protein in dauers (Jeong et al. 2009). Why daf-21 mRNA should be so highly expressed in the dauer stage remains unclear. One possibility is that $d a f-21$ mRNA may be accumulated in dauer larvae in readiness for the transition to normal development, where elevated levels of
DAF-21 could be required to chaperone proteins required for non-dauer development. Further studies would need to examine levels of DAF-21 over a time course, as the animal exits the dauer stage. Additional evidence for a role for DAF-21 in the dauer pathway comes from studies of a gain of function daf-21 mutant. These worms bear a single amino acid substitution (E292K) in DAF-21 and are dauerconstitutive (Daf-c), i.e. enter the dauer state under favourable conditions of growth due to a defect in chemosensory ability. This Daf-c phenotype is shared with a second mutant, daf-11, which encodes a protein homologous to transmembrane guanylyl cyclases. Both the daf-11 and the daf-21 Daf-c phenotypes can be rescued using an analogue of cGMP. It was proposed that DAF-21 was required to stabilize DAF-11 or another component in the cGMP pathway (Birnby et al. 2000). A better understanding of the key client proteins of DAF-21 in C. elegans would help explain the requirement for Hsp90 in different life cycle stages of the nematode.

While studies from this laboratory have failed to demonstrate a significant induction of DAF-21 in $C$. elegans following heat shock (as quantified by immuno-blotting with a specific antibody) (Thompson et al. 2001; Devaney et al. 2005), other studies using in situ hybridization with daf-21 specific probes have revealed differences in both the staining patterns and abundance of daf-21 mRNA in C. elegans upon heat shock (Inoue et al. 2003). At normal growth temperatures, DAF-21 is predominantly localized to the germline of C.elegans, as detected by antibody staining (Gillan et al. 2009) as well as in situ hybridization (Inoue et al. 2003). A genome-wide RNAi screen reported that knockdown of daf-21 leads to defects in oogenesis (Piano et al. 2000; Inoue et al. 2006). In more detailed experiments from this lab, it was shown that one of the most penetrant phenotypes obtained upon $d a f-21$ $(R N A i)$ was a protruding vulva and sterility in the $\mathrm{F}_{1}$ generation, due to a lack of gonad development (Gillan et al. 2009). Interestingly, Drosophila Hsp90 is expressed in the germline (Xiao and Lis, 1989) and in Xenopus, Hsp90 is expressed during oogenesis suggesting a conserved function between different species (Coumailleau et al. 1995). While the precise function of Hsp90 in the germline is still poorly understood, identification of DAF-21 client proteins can help explain mutant phenotypes, as exemplified by the interaction between the WEE-1.3 kinase and Hsp90. Here it was shown that DAF-21 indirectly regulates the meiotic prophase/metaphase transition during oocyte development through maintaining the activity of WEE-1.3 (Myt-1 orthologue in C. elegans), which is involved in cell cycle progression (Inoue et al. 2006).

The accumulation of DAF-21 in the germline of C. elegans is interesting in the context of recent studies, which have described a role for Hsp90 in 
various silencing pathways, including the piRNA and microRNA (miRNA) pathways (Izumi et al. 2013; Martinez and Gregory, 2013). These studies link the original observations of Lindquist and colleagues on the capacity of Hsp90 to buffer environmental change with a possible molecular mechanism. Altering the function of Hsp90 in Drosophila by mutation or by treatment with GA resulted in flies with various abnormalities of wings and eyes (Rutherford and Lindquist, 1998). It was proposed that high levels of cellular Hsp90 buffered pre-existing cryptic variation, which was then expressed when Hsp90 activity was compromised. However, the molecular mechanisms underlying these observations have remained elusive. Recent studies have shown that Hsp90 interacts in the Piwi pathway in Drosophila. piRNAs are a germline-specific class of small RNAs that silence transposons. Inhibition of Hsp90 function is proposed to inhibit the loading of RNA onto PIWI proteins (Izumi et al. 2013), resulting in the activation of transposons in Drosophila and the appearance of de novo mutations (Specchia et al. 2010; Gangaraju et al. 2011), suggesting one mechanism by which Hsp90 may regulate phenotypic change. Additional studies have implicated Hsp90 in epigenetic regulation of gene expression via its interaction with Trithorax (Trx), a chromatin remodelling factor (Ruden and Lu, 2008; Tariq et al. 2009). Trx is associated with active transcription and Hsp90 inhibition degraded Trx and resulted in a down-regulation in the expression of a number of genes. Genome-wide studies in Drosophila cells using chromatin immunoprecipitation showed that Hsp90 associated with multiple genes and that these were transcriptionally paused. Inhibition of Hsp90 released the pause, activating gene expression (Sawarkar et al. 2012).

Hsp90 is also involved in the loading of small interfering RNA duplexes (siRNA) and miRNA onto argonaute proteins in Drosophila and in human cells; argonaute proteins are the main components of the RNA Induced Silencing Complex (RISC). siRNA and microRNAs can only fulfil their function as post-transcriptional repressors of gene function (often referred to as the 'fine-tuners' of the genome) if they are successfully loaded onto these complexes (Iwasaki et al. 2010; Miyoshi et al. 2010). Whether Hsp90 plays similar roles in nematodes remains to be seen, but given the phenotypes of $d a f-21(R N A i)$ ( $\mathrm{F}_{1}$ sterility, protruding vulva phenotype, lack of gonad development, reduced brood size) and larval arrest in a homozygous daf-21 mutant strain, it is an area which warrants further investigation.

\section{HSP90 IN PARASITIC NEMATODES}

In comparison to the information available on DAF-21 in C. elegans, relatively little is known about Hsp90 in parasitic species. $h s p 90$ has been cloned and partially characterized from the filarial worm B. pahangi (Bp-hsp90) (Devaney et al. 2005) and from the clade I parasite $T$. spiralis (Yang et al. 2013). In common with most other parasitic nematodes, lymphatic filarial worms undergo a heat shock as part of their life cycle. The infection is transmitted to humans by the bite of a mosquito carrying the third stage larvae (L3) in the mouthparts and head. The L3 enter the lymphatics where they develop through two moults to adult male and female adult worms, which can live for approximately 8 years. Following sexual reproduction, the adult female releases microfilariae into the lymph which then migrate to the circulatory system, where they provide a reservoir of infection for the vector (summarized in Fig. 1B). The transfer of the L3 between vector and mammalian host is associated with an elevation in temperature from the ambient (mosquito) to $37^{\circ} \mathrm{C}$ (mammalian host). Using ${ }^{35} \mathrm{~S}$ methionine labelling, an increase in expression of a range of heat shock proteins, including Hsp90, was observed as L3 were shifted from 28 to $37^{\circ} \mathrm{C}$ (Jecock and Devaney, 1992). However, there is no evidence to suggest that the expression of $B p-h s p 90$ (either mRNA or protein) is significantly increased following exposure of adult worms to heat shock conditions (Thompson et al. 2001; Devaney et al. 2005), suggesting that most $B p-h s p 90$ is constitutively expressed. Parasitic nematodes secrete a range of molecules when cultured in serum-free medium (the so called excretory-secretory products or ES), and analysis of the ES of adult B. malayi demonstrated that B. malayi Hsp90 (Bm-Hsp90) was present (Kumari et al. 1994), a finding which has been confirmed in this laboratory using B. pahangi (Devaney et al. unpublished observations). Hsp90 is best characterized as a cytosolic chaperone, but studies on some cancer cells have shown that it can be expressed at the cell surface and secreted into medium (Eustace and Jay, 2004; Eustace et al. 2004). Extracellular Hsp90 was shown to be required for tumour cell invasion via the chaperoning of matrix metalloproteinases. It is difficult to envisage an extracellular function for $B p$-Hsp90 in adult B. pahangi, but it could conceivably be important for chaperoning and folding other secreted molecules.

While there are many similarities in the molecular architecture of DAF-21 and $B p-H s p 90$ there are also significant differences in the function of the molecule in the respective species. As referred to above, DAF-21 does not bind GA, while $B p-H s p 90$ does. The subtle complexities of the Hsp90 machinery in different nematodes was demonstrated in a study which attempted to rescue the $C$. elegans daf-21 mutant phenotype by heterologous expression of parasite $h s p 90$ genes (Gillan et al. 2009). Previous studies had demonstrated the efficacy of inter-species complementation experiments in transgenic $C$. elegans, where a parasite gene can rescue the $C$. elegans 
Table 1. Summary of $h s p 90$ inter-species rescue experiments in C. elegans. Extracted from Gillan et al. (2009)

\begin{tabular}{llll}
\hline \hline & C. elegans & H. contortus & B. pahangi \\
\hline Complementation of mutant & Yes & Partial rescues L2/L3 arrest & No rescue \\
RNAi & n/a & No rescue & No rescue \\
$\%$ id with C. elegans & $100 \%$ & $88 \%$ & $84 \%$ \\
\hline \hline
\end{tabular}

Table 2. Summary of $h s p 90$ inter-species rescue experiments in S. cerevisiae. Extracted from Palmer et al. (1995); Piper et al. (2003); Wider et al. (2009)

\begin{tabular}{lll}
\hline \hline Species & $\%$ id with S. cerevisiae & Complementation \\
\hline Escherichia coli & $36 \%$ & No \\
Homo sapiens & $59 \%$ & Yes \\
Trypanosoma cruzi & $63 \%$ & Yes \\
Plasmodium falciparum & $63 \%$ & Yes \\
\hline \hline
\end{tabular}

mutant phenotype and restore wild type traits (Kwa et al. 1995; Britton and Murray, 2002; Couthier et al. 2004; Massey et al. 2006). However, despite a high level of amino acid homology (84\% identical, 91\% similar), expression of a $B p-h s p 90$ transgene could not rescue a $C$. elegans daf-21 mutant. Similarly, no rescue was observed by expression of the $B p-h s p 90$ construct in wild type $C$. elegans, in which endogenous daf-21 levels were reduced by RNAi. In these experiments, $B p-h s p 90$ was introduced into $C$. elegans by microinjection of a plasmid construct containing the $B p-h s p 90$ coding sequence under the control of the C. elegans daf-21 promoter and 3'UTR regions, in an attempt to mimic the expression of the endogenous gene as closely as possible. To confirm that the parasite gene was efficiently transcribed in C. elegans, injection of a $B p-h s p 90$ Lac Z translational reporter construct demonstrated that the parasite Hsp90 was expressed in most tissues of the transformed worms and, importantly, that the B. pahangi protein expressed in C.elegans bound to GA beads in a pull-down experiment (Gillan et al. 2009). Despite these findings, complementation of the daf-21 mutant or daf-21(RNAi) worms was never observed. A more successful inter-species rescue was obtained using $h s p 90$ from $H$. contortus (Hc-hsp90), a trichostrongyloid nematode of sheep, which belongs to the same clade as C.elegans. $\mathrm{Hc}$-Hsp 90 is $88 \%$ identical and $93 \%$ similar to DAF-21 and experiments with an $H c-h s p 90$ construct provided partial rescue of the daf-21 mutant phenotypes. As control experiments had demonstrated that complementation with the wild-type $d a f-21$ in the same injection cassette restored the wild type phenotype of the daf-21 mutant worms, a 'gradient' of rescue was proposed, i.e. despite high sequence homology the B. pahangi transgene was unable to rescue the mutant, $H c-h s p 90$ was able to confer partial rescue but it required complementation with the wild-type $C$. elegans gene to completely rescue the mutant phenotypes and restore fertility (see Table 1 for summary). These results suggest that in metazoans, the ability to complement Hsp90 function may depend on factors other than sequence homology; successful rescue may require specific co-chaperones for full function of the transgene, or alternatively these data may reflect difference in the ability of the respective Hsp90 proteins to chaperone key client proteins. In contrast to the studies on nematode Hsp90, other interspecies complementation experiments using mutant Saccharomyces cerevisiae have been successful even when the degree of homology between the respective $h s p 90$ genes was relatively limited (see Table 2). Indeed, both C. elegans wild-type daf-21 and human $h s p 90 b$ were able to rescue an $S$. cerevisiae $h s p 90$ mutant despite sharing only $60 \cdot 5$ and $60 \cdot 3 \%$ sequence homology, respectively. However, in this case complementation required the presence of STI-1/Hop (Hsp organizing protein) indicating that the expression of co-chaperone proteins is of primary importance to the functionality of Hsp90 (Piper et al. 2003).

\section{HSP 90 CO-CHAPERONES IN NEMATODES}

The interaction of Hsp90 with client and cochaperone proteins is regulated by ATP-induced conformational changes in Hsp90, resulting in the folding and activation of substrate or 'client' proteins. Over the years, the number of Hsp90 client proteins has grown significantly and it has been shown to be essential in the maturation of many different types of protein in mammalian cells, including transcription factors, steroid receptors, serine/threonine and tyrosine kinases. A list of Hsp90 client proteins is curated by The Picard laboratory (http://www.picard.ch). 


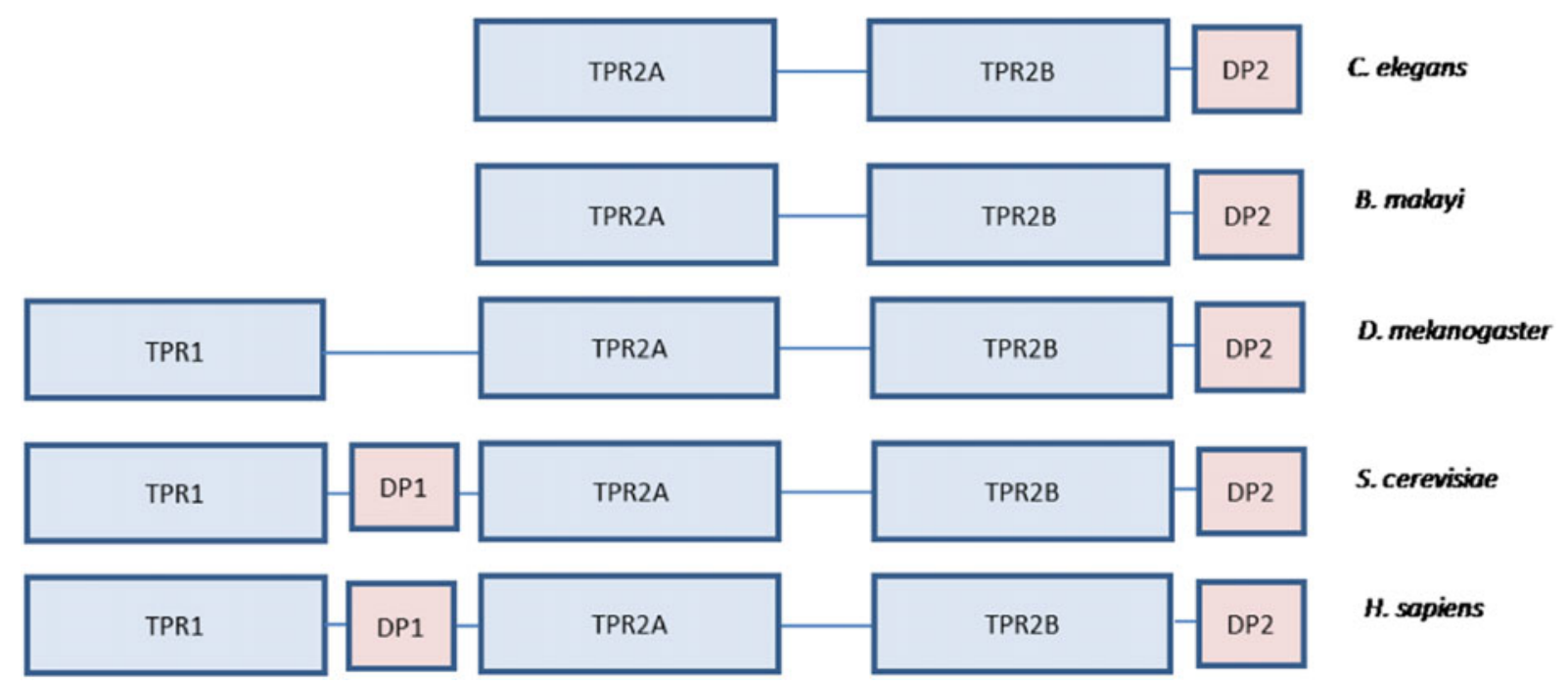

Fig. 3. Comparison of the domain structures of Hop from divergent species. TPR domains are shown in blue and DP domains in pink. Homologues of Hop show differences in domain organization. TPR1 and DP1 are absent in the nematode species C. elegans and B. malayi while only DP1 is lacking in D. melanogaster. All five domains are present in H. sapiens and S. cerevisiae. Adapted from Gaisier et al. (2009).

There are no published data from parasitic nematode species on the client proteins that require Hsp90 for function, but there is an extensive list of both predicted and confirmed clients for DAF-21 (http:// www.wormbase.org). Many of these clients have homologues in the human system, such as small ribosomal proteins, serine/threonine kinases and cyclin-dependent kinases, in addition to some 'worm-specific' proteins, such as those essential for pharyngeal pumping, a process required for food intake. While it is likely that at least some C.elegans client proteins will be similar in other nematodes, the degree of conservation is currently unknown.

The identification and function of co-chaperones in different species is of interest given their importance in the outcome of client protein maturation. For example, some Hsp90 clients require a select group of co-chaperones and alternative co-chaperones may have differential effects on client proteins (Riggs et al. 2004; Felts et al. 2007; Smith and Toft, 2008). These findings are strengthened by evidence that many cochaperones display mutually exclusive binding to Hsp90 (Pratt et al. 2004; Harst et al. 2005; Pearl and Prodromou, 2006). A study by Johnson and Brown illustrated the plasticity of the co-chaperone machinery in diverse eukaryotes and showed that the architecture of the Hsp90/co-chaperone machine varied in a species-specific manner. Their results suggested that with increasing complexity of the organism, additional co-factors may be required. While Hsp90 is universally required in metazoans, it is likely that the Hsp90 complex varies in different tissues/cells. Caenorhabditis elegans was shown to express orthologues of nine of the ten human Hsp90 co-chaperones used in the directed Psi-BLAST search against the complete $C$. elegans genome
(Johnson and Brown, 2009). The only co-chaperone absent in C. elegans was Cyp40, which was first identified in mammalian steroid receptor complexes (Riggs et al. 2004). However, another striking difference in $C$. elegans was shown to occur within the sequence of the adaptor protein Hop (STI-1 in C. elegans), which has an essential role in mediating interactions between Hsp70 and Hsp90. In most eukaryotes, Hop consists of five domains: three tetratricopeptide repeat (TPR) domains and two dipeptide (DP) repeats, which act as linker domains, arranged TPR1-DP1-TPR2A-TPR2BDP2 (Scheufler et al. 2000). However, C. elegans STI-1 lacks the TPR1 and DP1 domains (www. wormbase.org). This is an intriguing finding as, in other systems, the TPR1 domain has been shown to be essential for binding Hsp70, and for linking Hsp70 with Hsp90 (which binds Hop via TPR2A) (Scheufler et al. 2000). Hsp70 was observed to bind to C. elegans STI-1 despite the lack of the hypothetical binding site; however, in the presence of DAF-21, Hsp70 binding was completely abrogated suggesting that in $C$. elegans there may be no requirement for both chaperones to interact simultaneously, distinguishing C. elegans from other species (Gaiser et al. 2009). The lack of the TPR1 domain was also observed in the closely related Caenorhabditis briggsae and Caenorhabditis remanei. Interestingly, it appears this atypical Hop is not limited to the Caenorhabditis genus, as the B. malayi genome contains an orthologue of C. elegans STI-1, BMA-STI-1 (http://www. wormbase.org). This protein shares $65 \cdot 5 \%$ amino acid identity with $C$. elegans STI-1 and similarly appears to lack TPR1 and DP1 domains suggesting that this could be a nematode-wide scenario (see Fig. 3). 
In 2007, a genome-wide promoter analysis addressed the tissue-specific expression of most proteins in $C$. elegans and showed that DAF-21 was expressed in many different cell types. This analysis allowed the correlation of DAF-21 expression with the expression profiles of its presumed co-chaperone proteins (Dupuy et al. 2007). Analysing the differential expression of DAF-21 and its co-chaperones allows for some speculation on the cellular activity of the Hsp90/co-chaperone complexes, as it is likely that tissue localization corresponds to function (data accessed through www.wormbase.org). For example, co-chaperones P23 (ZC395.1), Hop (STI-1) and FKB-6 were all shown to be ubiquitously expressed in C. elegans, whereas PP5 (PPH-5) and CDC-37 are expressed only in the intestine and embryo respectively, suggesting a more specific role. Perhaps the best example of cellular location correlating with function is illustrated by the expression pattern of the TPRcontaining cofactor UNC-45 (uncoordinated), which is expressed in body wall muscle, intestinal muscle and vulval muscles. In C. elegans, the 95 rhomboidshaped body wall muscle cells comprise one of the major tissues of the adult worm (www.wormatlas. org). Down-regulation of UNC-45 leads to paralysis via decreased myosin assembly, whereas an excess of UNC-45 results in myosin accumulation, both of which result in defective myofibril organization (Barral et al. 2002; Landsverk et al. 2007). The details of how UNC-45 and DAF-21 work together are still unclear, although it has been reported that UNC-45 interacts with Hsp90 via a TPR domain (Russell et al. 1999; Scheufler et al. 2000; Barral et al. 2002) and myosin motor domains through its COOH-terminal regions (Barral et al. 1998, 2002). Elegant studies by $\mathrm{Ni}$ et al. demonstrated that DAF-21 and UNC-45 interact in pull-down experiments using C. elegans lysates and proposed that this interaction might have an inhibitory effect on the myosin-chaperoning activity of UNC-45 (Ni et al. 2011).

Online sources (http://www.wormbase.org) demonstrate that $C$. elegans encodes 80 TPR proteins, so perhaps the fact that only nine are known homologues of human Hsp90 co-chaperones is surprising (for comparison, the proteome of $S$. cerevisiae contains about 25 proteins with TPR domains, seven of which are confirmed to interact with either Hsp90 or Hsp70). In a recent study, Haslbeck et al. analysed previously uncharacterized TPR proteins, known to be associated with the Hsp90/Hsp70 complex. The entire proteome of $C$. elegans was analysed and scores were given to each protein based on the level of homology to known co-chaperone TPR proteins of Homo sapiens, S. cerevisiae and $C$. elegans. The proteins with the highest score for potential binding to Hsc70/Hsp70 and Hsp90 were the ten $C$.elegans TPR proteins used in the sample set (SGT-1, UNC-45, FKB-6, PPH-5, STI-1, HIP-1,
CHN-1, C56C10.10/AIP-1, C17G10.10/CNS-1). In addition, three uncharacterized $C$. elegans openreading frames with homologues in Drosophila or humans emerged as possible Hsp90 interactors. Two of these, C34B2.5 and ZK370.8 were shown to bind both Hsc70 and DAF-21 with low micromolar affinities; mutation of amino acids in the Hsp90 binding site for TPR proteins (EEVD sequence) was shown to disrupt the interaction. Interestingly, this study demonstrates that the majority of TPR proteins in $C$. elegans have no binding affinity for DAF-21 (Haslbeck et al. 2013).

\section{HSP90 AS A DRUG TARGET IN NEMATODES}

The realization that Hsp90 acted as a chaperone for various oncogenic proteins led to a major effort to develop novel small molecule inhibitors of Hsp90 for use in various tumours (Neckers et al. 1999). More recently the potential of Hsp90 inhibitors as novel chemotherapeutic agents for various parasitic infections has been studied (see other articles in this special issue). As referred to previously, there is a need for novel drugs to treat humans and animals infected with helminth parasites and studies in vitro have shown a dependence on Hsp90 in parasitic nematodes (Devaney et al. 2005) and in the trematode parasite Schistosoma japonicum (Wenkert et al. 2010). The design of new anthelmintics generally centres on attempts to establish and exploit molecular targets that are exclusive to the parasite, with the aim of minimizing potential damage to the host. Although this approach can be successful, an alternative course is to target a common pathway shared by the infectious agent and the host, which has evolved over time to perform different functions unique to the respective species. The benefits of focusing drug discovery on such pathways are two-fold; the scope for identifying new targets is broadened and not confined to parasite-specific molecules, many of which are hypothetical proteins of unknown function, and the ubiquity of such molecules in other systems may allow for drugs designed in this way to be used in other parasitic infections. The repurposing of compounds developed to treat other conditions is an attractive proposition for drug development for neglected tropical diseases, where the potential to recoup drug development costs is limited. In this respect, Hsp90 inhibitors have been shown to be effective against a variety of tropical pathogens including Plasmodium (Kumar et al. 2003; Shahinas et al. 2010, 2013), Trypanosoma (Pallavi et al. 2010) and Leishmania (Petersen et al. 2012).

Recent studies from this laboratory have focused on the potential of Hsp90 inhibitors as macrofilaricidal agents in filarial infection. Currently, the drugs used to control filarial nematodes in mass drug administration (MDA) programmes, such as diethylcarbamazine (DEC) and ivermectin, largely target 
the circulating microfilariae (Mf), resulting in reduced transmission rates. However, Mf repopulate the circulation necessitating continued treatment over the long reproductive lifespan of adult worms, incurring significant costs for control programmes and increasing the chances of resistance emerging (Prichard et al. 2012). It has long been a goal of WHO to identify a suitable drug that kills adult filarial worms but, to date, no such agent has been developed (Molyneux et al. 2003). At higher concentrations of drug, DEC can have macrofilaricidal activity, although in most long-term studies, Mf were shown to re-emerge in the blood of some patients, $1-5$ years post-treatment. This suggests either that a proportion of adult worms survived DEC treatment and recover Mf production or may reflect re-infection (Terhell et al. 2003). Targeting the Wolbachia intracellular endosymbiont of many pathogenic filarial worms with doxycycline remains the most promising new therapy that affects adult worms. However, this antibiotic is contraindicated in pregnant women and children and prolonged dosing is not ideal for MDA, but the search continues for a more satisfactory antibiotic (Hoerauf, 2008). While the $B$. malayi genome may yet illuminate novel parasite-specific drug targets, we have previously identified a requirement for Hsp90 as a possible weak spot in filarial nematodes. The prototype Hsp90 inhibitor, GA, a naturally occurring benzoquinone ansamycin, binds the N-terminal ATP pocket of Hsp90 disrupting its function and resulting in the degradation and/or inhibition of client proteins. In initial studies, in vitro exposure of $B$. pahangi adult female worms to $1 \mu \mathrm{M}$ GA (a concentration chosen as it inhibits mammalian Hsp90 activity) was shown to result in a significant reduction in Mf production from adult worms after $24 \mathrm{~h}$ and by $48 \mathrm{~h}$, Mf release had ceased completely (Devaney et al. 2005). As well as inhibiting Mf output, GA was shown to kill adult worms, as after 7 days of exposure to drug, $100 \%$ of adult female worms were dead. GA probably has a specific effect on adult worms (as well as inhibition of Mf output), as further experiments demonstrated that adult males were also killed by exposure to $1 \cdot 0 \mu \mathrm{M}$ GA. As referred to above, most species of filarial worms are known to harbour endosymbiotic bacteria, and to ensure that these effects were not a result of GA targeting the Wolbachia of B. pahangi, the experiments were repeated using the Wolbachia-free species Acanthocheilonema viteae and similar results were obtained. Comparable data were produced by Wenkert et al. who tested GA and a number of GA-derivatives against adult B. malayi in vitro. In their study, all four derivatives tested were active at concentrations down to $500 \mathrm{~nm}$. While these results show promise, GA suffers from limitations as a chemotherapeutic agent due to unacceptable levels of hepatoxicity and would not be suitable for use in filarial infection. Thus most recent studies on Hsp90 inhibitors have focused on novel small molecule inhibitors (Wenkert et al. 2010).

In subsequent studies, we investigated whether members of the purine-scaffold series of Hsp90 inhibitors, developed by the Chiosis laboratory (Chiosis and Tao, 2006; Taldone et al. 2011), would have activity against adult $B$. pahangi. In initial experiments, a fluorescence polarization (FP) assay, originally developed as a high-throughput screen for the detection of small molecule inhibitors of Hsp90 in tumour cells, was adapted to Brugia sp. (Taldone et al. 2010). The assay is based on the ability of small molecules to compete with the binding of fluorescently labelled GA to Hsp90 in cellular homogenates, thus negating the need for the production of purified recombinant protein as well as enabling investigation of Hsp90 in its native conformation. Previous studies had demonstrated that Hsp90 in tumour cells is present in multi-chaperone complexes with high ATPase activity and a higher affinity for N-terminal inhibitors compared with Hsp90 from normal cells, where it is present in a latent form with a reduced affinity for these inhibitors (Kamal et al. 2003). Subsequent studies confirmed this finding and showed that Hsp90-specific pulldowns using the purine scaffold compound, PU-H71 conjugated to a solid support, identified a complex of interacting proteins from tumour cells (Moulick et al. 2011). Interestingly, the affinity of $B p$-Hsp 90 for GA was shown to be similar to tumour cell Hsp90 in the FP assay, while extracts of $C$. elegans did not show significant binding, consistent with previous results. In addition, some selectivity was noted in the binding of the purine-scaffold compounds to $B p$-Hsp90 (Taldone et al. 2010); a 3-fold change in selectivity ratio was observed between PU-H71 and PU-WS10, two compounds with almost identical structure, suggesting that the FP assay could identify molecules which may specifically target parasite Hsp90.

In more recent work from this laboratory, we examined whether Hsp90 inhibitors might affect adult worms in vivo (Gillan et al. 2014). For this purpose we selected an isoxazole inhibitor, NVPAUY922, which had previously been demonstrated to exhibit anti-tumour activity in a mouse xenograft tumour model (Eccles et al. 2008; Garon et al. 2013). Experiments in vitro had shown NVP-AUY922 to be remarkably active against both adult worms and Mf at very low concentrations, killing Mf at concentrations down to $1.56 \mathrm{nM}$ and $50 \%$ of adult worms at $25 \mathrm{nM}$. Using a model system in which adult $B$. pahangi worms are transplanted into the peritoneal cavity of mice (Devaney et al. 2002), we demonstrated that administration of three doses of NVP-AUY922 at $50 \mathrm{mg} \mathrm{kg}^{-1}$ effectively killed adult worms (Gillan et al. 2014). No weight loss or other deleterious effects were observed in treated animals over the time course. While these experiments provide proof of principle that inhibition of 
Hsp90 is lethal to adult filarial worms in vivo, further experiments are required with different routes of drug administration and different doses of drug.

\section{CONCLUSIONS}

Recent studies on the free-living model nematode C. elegans have shed new light on the mechanisms of Hsp90 function in metazoans, particularly in relation to the tissue-specific requirement for certain cochaperones. Additional studies will be required to fully explain the apparent resistance of $C$. elegans to Hsp90 inhibitors and the molecular mechanisms underlying this phenomenon. However, given the studies reviewed above it is likely that the function of Hsp90 differs between free-living nematodes and their parasitic counterparts. It is possible that part of this discrepancy will be explained by differences in the Hsp90 interactome in free-living and parasitic species, such as filarial worms, perhaps equivalent to the differences in Hsp90 function in normal versus tumour cells. While aspects of their basic biology, such as moulting, are conserved amongst all nematodes, there are significant differences between free-living and parasitic species in life cycles, modes of transmission, reproduction and dependence on hosts. As momentum to eliminate neglected tropical diseases grows, the prospect of repositioning existing drugs is an appealing one. However, while preliminary results show that chemical inhibition of Hsp90 is lethal to adult filarial worms, further research is required to determine whether Hsp90 truly represents an 'Achilles heel' in filarial nematodes, suitable for exploitation as a chemotherapeutic target.

\section{ACKNOWLEDGEMENTS}

We acknowledge the support for our studies on Hsp90 from the Wellcome Trust (grant number $076734 / \mathrm{Z} / 05 / \mathrm{Z}$ ) and the BBSRC (grant number BB/E013473/1) and we would like to thank Dr Collette Britton and Dr Jane Kinnaird for critical reading of this manuscript.

\section{REFERENCES}

Abad, P., Gouzy, J., Aury, J. M., Castagnone-Sereno, P., Danchin, E. G., Deleury, E., Perfus-Barbeoch, L., Anthouard, V., Artiguenave, F., Blok, V.C., Caillaud, M. C. and Coutinho, P.M. (2008). Genome sequence of the metazoan plant-parasitic nematode Meloidogyne incognita. Nature Biotechnology 26, 909-915.

Barral, J. M., Bauer, C. C., Ortiz, I. and Epstein, H. F. (1998). Unc-45 mutations in Caenorhabditis elegans implicate a CRO1/She4p-like domain in myosin assembly. Fournal of Cell Biology 143, 1215-1225.

Barral, J. M., Hutagalung, A.H., Brinker, A., Hartl, F. U. and Epstein, H. F. (2002). Role of the myosin assembly protein UNC-45 as a molecular chaperone for myosin. Science 295, 669-671. doi: 10.1126/ science. 1066648

Birnby, D. A., Link, E. M., Vowels, J. J., Tian, H., Colacurcio, P. L. and Thomas, J. H. (2000). A transmembrane guanylyl cyclase (DAF-11) and Hsp90 (DAF-21) regulate a common set of chemosensory behaviors in Caenorhabditis elegans. Genetics 155, 85-104.
Blaxter, M. L., De Ley, P., Garey, J. R., Liu, L.X., Scheldeman, P., Vierstraete, A., Vanfleteren, J. R., Mackey, L. Y., Dorris, M., Frisse, L. M., Vida, J. T. and Thomas, W. K. (1998). A molecular evolutionary framework for the phylum Nematoda. Nature 392, 71-75. doi: $10.1038 / 32160$.

Britton, C. and Murray, L. (2002). A cathepsin L protease essential for Caenorhabditis elegans embryogenesis is functionally conserved in parasitic nematodes. Molecular and Biochemical Parasitology 122, 21-33.

Burns, A. R., Wallace, I. M., Wildenhain, J., Tyers, M., Giaever, G., Bader, G. D., Nislow, C., Cutler, S. R. and Roy, P. J. (2010). A predictive model for drug bioaccumulation and bioactivity in Caenorhabditis elegans. Nature Chemical Biology 6, 549-557. doi: 10.1038/nchembio.380.

Candido, E. P., Jones, D., Dixon, D. K., Graham, R. W., Russnak, R. H. and Kay, R. J. (1989). Structure, organization, and expression of the 16 kDa heat shock gene family of Caenorhabditis elegans. Genome 31, 690-697. Chiosis, G. and Tao, H. (2006). Purine-scaffold Hsp90 inhibitors. IDrugs 9, 778-782.

Coumailleau, P., Billoud, B., Sourrouille, P., Moreau, N. and Angelier, N. (1995). Evidence for a $90 \mathrm{kDa}$ heat-shock protein gene expression in the amphibian oocyte. Developmental Biology 168, 247-258. doi: 10.1006/dbio.1995.1077.

Couthier, A., Smith, J., Mcgarr, P., Craig, B. and Gilleard, J. S. (2004). Ectopic expression of a Haemonchus contortus GATA transcription factor in Caenorhabditis elegans reveals conserved function in spite of extensive sequence divergence. Molecular and Biochemical Parasitology 133, 241-253.

Dalley, B. K. and Golomb, M. (1992). Gene expression in the Caenorhabditis elegans dauer larva: developmental regulation of Hsp90 and other genes. Developmental Biology 151, 80-90.

David, C. L., Smith, H. E., Raynes, D. A., Pulcini, E. J. and Whitesell, L. (2003). Expression of a unique drug-resistant Hsp90 ortholog by the nematode Caenorhabditis elegans. Cell Stress and Chaperones 8, 93104.

Desjardins, C. A., Cerqueira, G.C., Goldberg, J.M., Dunning Hotopp, J. C., Haas, B. J., Zucker, J., Ribeiro, J.M., Saif, S., Levin, J.Z., Fan, L., Zeng, Q., Russ, C., Wortman, J. R., Fink, D. L., Birren, B.W. and Nutman, T.B. (2013). Genomics of Loa loa, a Wolbachia-free filarial parasite of humans. Nature Genetics 45, 495-500. doi: 10.1038/ng.2585.

Devaney, E., Gillan, V., Wheatley, I., Jenson, J., O'connor, R. and Balmer, P. (2002). Interleukin-4 influences the production of microfilariae in a mouse model of Brugia infection. Parasite Immunology 24, 29-37.

Devaney, E., O'Neill, K., Harnett, W., Whitesell, L. and Kinnaird, J. H. (2005). Hsp90 is essential in the filarial nematode Brugia pahangi. International fournal for Parasitology 35, 627-636.

Dieterich, C., Clifton, S.W., Schuster, L. N., Chinwalla, A., Delehaunty, K., Dinkelacker, I., Fulton, L., Fulton, R., Godfrey, J. Minx, P., Mitreva, M., Roeseler, W., Tian, H., Witte, H., Yang, S. P., Wilson, R. K. and Sommer, R. J. (2008). The Pristionchus pacificus genome provides a unique perspective on nematode lifestyle and parasitism. Nature Genetics 40, 1193-1198.

Dupuy, D., Bertin, N., Hidalgo, C. A., Venkatesan, K., Tu, D., Lee, D. Rosenberg, J., Svrzikapa, N., Blanc, A., Carnec, A., Carvunis, A. R., Pulak, R., Shingles, J., Reece-Hoyes, J., Hunt-Newbury, R., Viveiros, R., Mohler, W. A., Tasan, M., Roth, F. P., Le Peuch, C., Hope, I. A., Johnsen, R., Moerman, D. G., Barabasi, A. L., Baillie, D. and Vidal, M. (2007). Genome-scale analysis of in vivo spatiotemporal promoter activity in Caenorhabditis elegans. Nature Biotechnology 25, 663-668. doi: 10.1038/nbt1305.

Eccles, S. A., Massey, A., Raynaud, F. I., Sharp, S. Y., Box, G., Valenti, M., Patterson, L., De Haven Brandon, A., Gowan, S., Boxall, F., Aherne, W., Rowlands, M., Hayes, A., Martins, V., Urban, F., Boxall, K., Prodromou, C., Pearl, L., James, K., Matthews, T.P., Cheung, K. M., Kalusa, A., Jones, K., McDonald, E., Barril, X., Brough, P. A., Cansfield, J. E., Dymock, B., Drysdale, M. J., Finch, H., Howes, R., Hubbard, R. E., Surgenor, A., Webb, P., Wood, M., Wright, L. and Workman, P. (2008). NVPAUY922: a novel heat shock protein 90 inhibitor active against xenograft tumor growth, angiogenesis, and metastasis. Cancer Research 68 2850-2860. doi: 10.1158/0008-5472.can-07-5256.

Eustace, B. K. and Jay, D. G. (2004). Extracellular roles for the molecular chaperone, hsp90. Cell Cycle 3, 1098-1100.

Eustace, B. K., Sakurai, T., Stewart, J. K., Yimlamai, D., Unger, C., Zehetmeier, C., Lain, B., Torella, C., Henning, S. W., Beste, G., Scroggins, B. T., Neckers, L., Ilag, L. L. and Jay, D. G. (2004). 
Functional proteomic screens reveal an essential extracellular role for hsp90 alpha in cancer cell invasiveness. Nature Cell Biology 6, 507-514. doi: $10.1038 /$ ncb1131.

Felts, S. J., Karnitz, L. M. and Toft, D. O. (2007). Functioning of the Hsp90 machine in chaperoning checkpoint kinase I (Chk1) and the progesterone receptor (PR). Cell Stress and Chaperones 12, 353-363.

Gaiser, A. M., Brandt, F. and Richter, K. (2009). The non-canonical Hop protein from Caenorhabditis elegans exerts essential functions and forms binary complexes with either Hsc70 or Hsp90. Fournal of Molecular Biology 391, 621-634. doi: 10.1016/j.jmb.2009.06.051.

Garon, E. B., Finn, R.S., Hamidi, H., Dering, J., Pitts, S., Kamranpour, N., Desai, A. J., Hosmer, W., Ide, S., Avsar, E., Jensen, M. R., Quadt, C., Liu, M., Dubinett, S. M. and Slamon, D. J. (2013). The HSP90 inhibitor NVP-AUY922 potently inhibits non-small cell lung cancer growth. Molecular Cancer Therapy 12, 890-900. doi: 10.1158/1535-7163.mct-12-0998.

Gangaraju, V. K., Yin, H., Weiner, M. M., Wang, J., Huang, X. A. and Lin, H. (2011). Drosophila Piwi functions in Hsp90-mediated suppression of phenotypic variation. Nature Genetics 43, 153-158. doi: 10.1038/ng.743. Geary, T. G., Woo, K., McCarthy, J. S., Mackenzie, C. D., Horton, J., Prichard, R. K., De Silva, N. R., Olliaro, P. L., Lazdins-Helds, J. K., Engels, D. A. and Bundy, D. A. (2010). Unresolved issues in anthelmintic pharmacology for helminthiases of humans. International fournal for Parasitology 40, 1-13. doi: 10.1016/j.ijpara.2009.11.001.

Ghedin, E., Wang, S., Spiro, D., Caler, E., Zhao, Q., Crabtree, J., Allen, J. E., Delcher, A. L., Guiliano, D. B., Miranda-Saavedra, D., Angiuoli, S. V. and Creasy, T. (2007). Draft genome of the filarial nematode parasite Brugia malayi. Science 317, 1756-1760.

Gillan, V., Maitland, K., McCormack, G., Nik Him, N. A. and Devaney, E. (2009). Functional genomics of hsp-90 in parasitic and freeliving nematodes. International Fournal for Parasitology 39, 1071-1081. doi: S0020-7519(09)00167-2 [pii]10.1016/j.ijpara.2009.02.024.

Gillan, V., O’Neill, K., Maitland, K., Sverdrup, F. M. and Devaney, E. (2014). A repurposing strategy for Hsp90 inhibitors demonstrates their potency against filarial nematodes. PLoS Neglected Tropical Disease 8, e2699. doi: 10.1371/journal.pntd.0002699.

Gilleard, J. S. (2006). Understanding anthelmintic resistance: the need for genomics and genetics. International fournal for Parasitology 36, 1227-1239. doi: 10.1016/j.ijpara.2006.06.010.

Godel, C., Kumar, S., Koutsovoulos, G., Ludin, P., Nilsson, D., Comandatore, F., Wrobel, N., Thompson, M., Schmid, C. D., Goto, S., Bringaud, F., Wolstenholme, A., Bandi, C., Epe, C., Kaminsky, R., Blaxter, M. and Maser, P. (2012). The genome of the heartworm, Dirofilaria immitis, reveals drug and vaccine targets. Fournal of the Federation of American Societies for Experimental Biology 26, 4650-4661. doi: 10.1096/ fj.12-205096.

Golden, J. W. and Riddle, D. L. (1982). A pheromone influences larval development in the nematode Caenorhabditis elegans. Science 218, 578-580. Harst, A., Lin, H. and Obermann, W. M. (2005). Aha1 competes with Hop, p50 and p23 for binding to the molecular chaperone Hsp90 and contributes to kinase and hormone receptor activation. Biochemical fournal 387, 789-796. doi: 10.1042/BJ20041283.

Hashmi, S., Wang, Y., Parhar, R.S., Collison, K.S., Conca, W., Al-Mohanna, F. and Gaugler, R. (2013). A C. elegans model to study human metabolic regulation. Nutrition and Metabolism 10, 31. doi: 10.1186/ 1743-7075-10-31

Haslbeck, V., Eckl, J. M., Kaiser, C. J., Papsdorf, K., Hessling, M. and Richter, K. (2013). Chaperone-interacting TPR proteins in Caenorhabditis elegans. Fournal of Molecular Biology 425, 2922-2939. doi: 10.1016/j. jmb.2013.05.019.

Him, N. A., Gillan, V., Emes, R. D., Maitland, K. and Devaney, E. (2009). Hsp-90 and the biology of nematodes. BMC Evolutionary Biology $\mathbf{9}$, 254. doi: 10.1186/1471-2148-9-254.

Hoerauf, A. (2008). Filariasis: new drugs and new opportunities for lymphatic filariasis and onchocerciasis. Current Opinion in Infectious Disease 21, 673-681. doi: 10.1097/QCO.0b013e328315cde7.

Inoue, T., Takamura, K., Yamae, H., Ise, N., Kawakami, M., Tabuse, Y., Miwa, J. and Yamaguchi, Y. (2003). Caenorhabditis elegans DAF-21 (Hsp90) is characteristically and predominantly expressed in germline cells: spatial and temporal analysis. Development Growth and Differentiation 45, 369-376.

Inoue, T., Hirata, K., Kuwana, Y., Fujita, M., Miwa, J., Roy, R. and Yamaguchi, Y. (2006). Cell cycle control by daf-21/Hsp90 at the first meiotic prophase/metaphase boundary during oogenesis in Caenorhabditis elegans. Development Growth and Differentiation 48, 25-32. doi: 10.1111/ j.1440-169X.2006.00841.x.

Iwasaki, S., Kobayashi, M., Yoda, M., Sakaguchi, Y., Katsuma, S., Suzuki, T. and Tomari, Y. (2010). Hsc70/Hsp90 chaperone machinery mediates ATP-dependent RISC loading of small RNA duplexes. Molecular Cell 39, 292-299. doi: 10.1016/j.molcel.2010.05.015.

Izumi, N., Kawaoka, S., Yasuhara, S., Suzuki, Y., Sugano, S., Katsuma, S. and Tomari, Y. (2013). Hsp90 facilitates accurate loading of precursor piRNAs into Piwi proteins. RNA 19, 896-901. doi: 10.1261/ rna.037200.112.

Jecock, R. M. and Devaney, E. (1992). Expression of small heat shock proteins by the third-stage larva of Brugia pahangi. Molecular and Biochemical Parasitology 56, 219-226.

Jeong, P.Y., Na, K., Jeong, M. J., Chitwood, D., Shim, Y.H. and Paik, Y. K. (2009). Proteomic analysis of Caenorhabditis elegans. Methods in Molecular Biology 519, 145-169. doi: 10.1007/978-1-59745281-6_10.

Jex, A. R., Liu, S., Li, B., Young, N.D., Hall, R.S., Li, Y., Yang, L., Zeng, N., Xu, X., Xiong, Z., Chen, F., Wu, X., Zhang, G., Fang, X., Kang, Y., Anderson, G. A., Harris, T. W., Campbell, B. E., Vlaminck, J., Wang, T., Cantacessi, C., Schwarz, E. M., Ranganathan, S., Geldhof, P., Nejsum, P., Sternberg, P. W., Yang, H., Wang, J., Wang, J. and Gasser, R. B. (2011). Ascaris suum draft genome. Nature 479, 529-533. doi: 10.1038/nature10553.

Johnson, J. L. and Brown, C. (2009). Plasticity of the Hsp90 chaperone machine in divergent eukaryotic organisms. Cell Stress and Chaperones $\mathbf{1 4}$ 83-94. doi: 10.1007/s12192-008-0058-9.

Jones, D., Dixon, D. K., Graham, R. W. and Candido, E.P. (1989). Differential regulation of closely related members of the hsp16 gene family in Caenorhabditis elegans. DNA 8, 481-490.

Jones, S. J., Riddle, D. L., Pouzyrev, A. T., Velculescu, V.E., Hillier, L., Eddy, S. R., Stricklin, S. L., Baillie, D. L., Waterston, R. and Marra, M. A. (2001). Changes in gene expression associated with developmental arrest and longevity in Caenorhabditis elegans. Genome Research 11, 1346-1352. doi: 10.1101/gr.184401.

Kamal, A., Thao, L., Sensintaffar, J., Zhang, L., Boehm, M.F., Fritz, L. C. and Burrows, F. J. (2003). A high-affinity conformation of Hsp90 confers tumour selectivity on Hsp90 inhibitors. Nature 425, 407-410. doi: 10.1038/nature01913.

Kirienko, N. V., Mani, K. and Fay, D. S. (2010). Cancer models in Caenorhabditis elegans. Development Dynamics 239, 1413-1448. doi: 10.1002/dvdy.22247.

Kumar, R., Musiyenko, A. and Barik, S. (2003). The heat shock protein 90 of Plasmodium falciparum and antimalarial activity of its inhibitor, geldanamycin. Malaria fournal 2, 30. doi: 10.1186/1475-2875-2-30

Kumari, S., Lillibridge, C. D., Bakeer, M., Lowrie, R. C., Jr., Jayaraman, K. and Philipp, M. T. (1994). Brugia malayi: the diagnostic potential of recombinant excretory/secretory antigens. Experimental Parasitology 79, 489-505. doi: 10.1006/expr.1994.1110.

Kwa, M. S., Veenstra, J. G., Van Dijk, M. and Roos, M. H. (1995). Betatubulin genes from the parasitic nematode Haemonchus contortus modulate drug resistance in Caenorhabditis elegans. Fournal of Molecular Biology 246, 500-510. doi: 10.1006/jmbi.1994.0102.

Laing, R., Kikuchi, T., Martinelli, A., Tsai, I. J., Beech, R. N., Redman, E., Holroyd, N., Bartley, D. J., Beasley, H., Britton, C., Curran, D., Devaney, E., Gilabert, A., Hunt, M., Jackson, F., Johnston, S. L., Kryukov, I., Li, K., Morrison, A. A., Reid, A. J., Sargison, N., Saunders, G. I., Wasmuth, J. D., Wolstenholme, A., Berriman, M., Gilleard, J. S. and Cotton, J. A. (2013). The genome and transcriptome of Haemonchus contortus, a key model parasite for drug and vaccine discovery. Genome Biology 14, R88. doi: 10.1186/gb-2013-14-8-r88. Landsverk, M. L., Li, S., Hutagalung, A. H., Najafov, A., Hoppe, T., Barral, J. M. and Epstein, H. F. (2007). The UNC-45 chaperone mediates sarcomere assembly through myosin degradation in Caenorhabditis elegans. Fournal of Cell Biology 177, 205-210. doi: 10.1083/jcb.200607084.

Li, J. and Le, W. (2013). Modeling neurodegenerative diseases in Caenorhabditis elegans. Experimental Neurology 250C, 94-103. doi: 10.1016/j.expneurol.2013.09.024.

Martinez, N. J. and Gregory, R. I. (2013). Argonaute2 expression is post-transcriptionally coupled to microRNA abundance. $R N A 19,605-612$. doi: 10.1261/rna.036434.112.

Massey, H. C., Jr., Bhopale, M. K., Li, X., Castelletto, M. and Lok, J. B. (2006). The fork head transcription factor FKTF-1b from Strongyloides stercoralis restores DAF-16 developmental function to mutant Caenorhabditis elegans. International fournal for Parasitology 36, 347-352. doi: 10.1016/j.ijpara.2005.11.007.

Millson, S. H., Chua, C.S., Roe, S. M., Polier, S., Solovieva, S., Pearl, L. H., Sim, T.S., Prodromou, C. and Piper, P.W. (2011). Features of the Streptomyces hygroscopicus HtpG reveal how partial geldanamycin resistance can arise with mutation to the ATP binding pocket of a eukaryotic Hsp90. Fournal of the Federation of American Societies for Experimental Biology 25, 3828-3837. doi: 10.1096/fj.11-188821. 
Mitreva, M., Jasmer, D. P., Zarlenga, D. S., Wang, Z., Abubucker, S., Martin, J., Taylor, C. M., Yin, Y., Fulton, L., Minx, P., Yang, S.P. Warren, W. C., Fulton, R.S., Bhonagiri, V., Zhang, X., Hallsworth-Pepin, K., Clifton, S. W., McCarter, J.P., Appleton, J., Mardis, E. R. and Wilson, R. K. (2011). The draft genome of the parasitic nematode Trichinella spiralis. Nature Genetics 43, 228-235. doi: 10.1038/ ng.769.

Miyoshi, T., Takeuchi, A., Siomi, H. and Siomi, M. C. (2010). A direct role for Hsp90 in pre-RISC formation in Drosophila. Nature Structural and Molecular Biology 17, 1024-1026. doi: 10.1038/nsmb.1875.

Molyneux, D. H., Bradley, M., Hoerauf, A., Kyelem, D. and Taylor, M. J. (2003). Mass drug treatment for lymphatic filariasis and onchocerciasis. Trends in Parasitology 19, 516-522.

Moulick, K., Ahn, J.H., Zong, H., Rodina, A., Cerchietti, L., Gomes Dagama, E. M., Caldas-Lopes, E., Beebe, K., Perna, F., Hatzi, K., Vu, L.P., Zhao, X., Zatorska, D., Taldone, T. Smith-Jones, P., Alpaugh, M., Gross, S.S., Pillarsetty, N., Ku, T., Lewis, J.S., Larson, S. M., Levine, R., Erdjument-Bromage, H., Guzman, M. L., Nimer, S. D., Melnick, A., Neckers, L. and Chiosis, G. (2011). Affinity-based proteomics reveal cancer-specific networks coordinated by Hsp90. Nature Chemical Biology 7, 818-826. doi: 10.1038/nchembio.670

Neckers, L., Mimnaugh, E. and Schulte, T. W. (1999). Hsp90 as an anti-cancer target. Drug Resistance Update 2, 165-172. doi: 10.1054/ drup.1999.0082

Ni, W., Hutagalung, A. H., Li, S. and Epstein, H. F. (2011). The myosinbinding UCS domain but not the Hsp90-binding TPR domain of the UNC45 chaperone is essential for function in Caenorhabditis elegans. Fournal of Cell Science 124, 3164-3173. doi: 10.1242/jcs.087320.

Nicol, J. M., Turner, S. J., Coyne, D. L., Den Nijs, L., Hockland, S. and Maafi, Z. T. (2011). Current nematode threats to world agriculture In Genomics and Molecular Genetics of Plant-Nematode Interactions (ed. Jones, J., Gheysen, G. and Fenoll, C.), pp. 21-43. Springer, Dordrecht, the Netherlands.

Opperman, C. H., Bird, D. M., Williamson, V.M., Rokhsar, D.S., Burke, M., Cohn, J., Cromer, J., Diener, S., Gajan, J., Graham, S., Houfek, T. D., Liu, Q., Mitros, T., Schaff, J., Schaffer, R., Scholl, E. Sosinski, B. R., Thomas, V.P. and Windham, E. (2008). Sequence and genetic map of Meloidogyne hapla: a compact nematode genome for plant parasitism. Proceedings of the National Academy of Sciences USA 105 14802-14807.

Pallavi, R., Roy, N., Nageshan, R. K., Talukdar, P., Pavithra, S. R., Reddy, R., Venketesh, S., Kumar, R., Gupta, A. K., Singh, R. K. Yadav, S. C. and Tatu, U. (2010). Heat shock protein 90 as a drug target against protozoan infections: biochemical characterization of Hsp90 from Plasmodium falciparum and Trypanosoma evansi and evaluation of its inhibitor as a candidate drug. Fournal of Biological Chemistry 285, 37964-37975. doi: 10.1074/jbc.M110.155317.

Palmer, G., Louvion, J.F., Tibbetts, R. S., Engman, D. M. and Picard, D. (1995). Trypanosoma cruzi heat-shock protein 90 can functionally complement yeast. Molecular and Biochemical Parasitology $\mathbf{7 0}$ 199-202.

Pearl, L. H. and Prodromou, C. (2006). Structure and mechanism of the Hsp90 molecular chaperone machinery. Annual Review of Biochemistry 75 , 271-294. doi: 10.1146/annurev.biochem.75.103004.142738.

Petersen, A. L., Guedes, C.E., Versoza, C. L., Lima, J. G., De Freitas, L. A., Borges, V. M. and Veras, P. S. (2012). 17-AAG kills intracellular Leishmania amazonensis while reducing inflammatory responses in infected macrophages. PLoS One 7, e49496. doi: 10.1371/ journal.pone.0049496.

Piano, F., Schetter, A. J., Mangone, M., Stein, L. and Kemphues, K. J. (2000). RNAi analysis of genes expressed in the ovary of Caenorhabditis elegans. Current Biology 10, 1619-1622.

Piper, P.W., Panaretou, B., Millson, S. H., Trumana, A., Mollapour, M., Pearl, L.H. and Prodromou, C. (2003). Yeast is selectively hypersensitised to heat shock protein 90 (Hsp90)-targeting drugs with heterologous expression of the human Hsp90beta, a property that can be exploited in screens for new Hsp90 chaperone inhibitors. Gene 302, 165-170

Pratt, W. B., Galigniana, M. D., Harrell, J. M. and Defranco, D. B. (2004). Role of Hsp90 and the Hsp90-binding immunophilins in signalling protein movement. Cell Signalling 16, 857-872. doi: 10.1016/j.cellsig.2004.02.004.

Prichard, R. K., Basanez, M. G., Boatin, B. A., McCarthy, J. S., Garcia, H. H., Yang, G. J., Sripa, B. and Lustigman, S. (2012). A research agenda for helminth diseases of humans: intervention for control and elimination. PLoS Neglected Tropical Diseases 6, e1549. doi: 10.1371/ journal.pntd.0001549.
Prodromou, C., Nuttall, J. M., Millson, S. H., Roe, S. M., Sim, T. S., Tan, D., Workman, P., Pearl, L. H. and Piper, P. W. (2009). Structural basis of the radicicol resistance displayed by a fungal Hsp90. ACS Chemical Biology 4, 289-297. doi: 10.1021/cb9000316.

Rae, R., Riebesell, M., Dinkelacker, I., Wang, Q., Herrmann, M. Weller, A. M., Dieterich, C. and Sommer, R. J. (2008). Isolation of naturally associated bacteria of necromenic Pristionchus nematodes and fitness consequences. Fournal of Experimental Biology 211, 1927-1936. doi: 10.1242/jeb.014944

Riggs, D. L., Cox, M. B., Cheung-Flynn, J., Prapapanich, V., Carrigan, P. E. and Smith, D. F. (2004). Functional specificity of cochaperone interactions with Hsp90 client proteins. Critical Reviews in Biochemistry and Molecular Biology 39, 279-295. doi: 10.1080/ 10409230490892513

Ruden, D. M. and Lu, X. Y. (2008). Hsp90 affecting chromatin remodeling might explain transgenerational epigenetic inheritance in Drosophila. Current Genomics 9, 500-508. doi: 10.2174/138920208786241207.

Russell, L. C., Whitt, S. R., Chen, M.S. and Chinkers, M. (1999). Identification of conserved residues required for the binding of a tetratricopeptide repeat domain to heat shock protein 90. Fournal of Biological Chemistry 274, 20060-20063.

Rutherford, S. L. and Lindquist, S. (1998). Hsp90 as a capacitor for morphological evolution. Nature 396, 336-342. doi: 10.1038/24550.

Sawarkar, R., Sievers, C. and Paro, R. (2012). Hsp90 globally targets paused RNA polymerase to regulate gene expression in response to environmental stimuli. Cell 149, 807-818.

Scheufler, C., Brinker, A., Bourenkov, G., Pegoraro, S., Moroder, L., Bartunik, H., Hartl, F. U. and Moarefi, I. (2000). Structure of TPR domain-peptide complexes: critical elements in the assembly of the Hsp70Hsp90 multichaperone machine. Cell 101, 199-210. doi: 10.1016/S00928674(00)80830-2.

Schwarz, E. M., Korhonen, P. K., Campbell, B. E., Young, N. D. Jex, A. R., Jabbar, A., Hall, R.S., Mondal, A., Howe, A.C., Pell, J., Hofmann, A., Boag, P. R., Zhu, X. Q., Gregory, T. R., Loukas, A., Williams, B. A., Antoshechkin, I., Brown, C. T., Sternberg, P. W. and Gasser, R. B. (2013). The genome and developmental transcriptome of the strongylid nematode Haemonchus contortus. Genome Biology 14, R89. doi: 10.1186/gb-2013-14-8-r89.

Shahinas, D., Liang, M., Datti, A. and Pillai, D. R. (2010). A repurposing strategy identifies novel synergistic inhibitors of Plasmodium falciparum heat shock protein 90. Fournal of Medicinal Chemistry 53, 35523557. doi: 10.1021/jm901796s

Shahinas, D., Folefoc, A., Taldone, T., Chiosis, G., Crandall, I. and Pillai, D. R. (2013). A purine analog synergizes with chloroquine (CQ) by targeting Plasmodium falciparum Hsp90 (PfHsp90). PLoS One 8, e75446. doi: 10.1371/journal.pone.0075446.

Smith, D. F. and Toft, D. O. (2008). Minireview: the intersection of steroid receptors with molecular chaperones: observations and questions. Molecular Endocrinology 22, 2229-2240. doi: 10.1210/me.20080089 .

Specchia, V., Piacentini, L., Tritto, P., Fanti, L., D’Alessandro, R., Palumbo, G., Pimpinelli, S. and Bozzetti, M. P. (2010). Hsp90 prevents phenotypic variation by suppressing the mutagenic activity of transposons. Nature 463, 662-665. doi: 10.1038/nature08739.

Stein, L.D., Bao, Z., Blasiar, D., Blumenthal, T., Brent, M. R., Chen, N., Chinwalla, A., Clarke, L., Clee, C., Coghlan, A., Coulson, A., D'Eustachio, P., Fitch, D. H., Fulton, L. A Fulton, R.E., Griffiths-Jones, S., Harris, T.W., Hillier, L. W., Kamath, R., Kuwabara, P.E., Mardis, E. R., Marra, M. A., Miner, T. L., Minx, P., Mullikin, J.C., Plumb, R. W., Rogers, J., Schein, J.E., Sohrmann, M., Spieth, J., Stajich, J.E., Wei, C., Willey, D., Wilson, R.K., Durbin, R. and Waterston, R. H. (2003). The genome sequence of Caenorhabditis briggsae: a platform for comparative genomics. PLoS Biology 1, E45. doi: 10.1371/journal pbio.0000045.

Taldone, T., Gillan, V., Sun, W., Rodina, A., Patel, P., Maitland, K., O'Neill, K., Chiosis, G. and Devaney, E. (2010). Assay strategies for the discovery and validation of therapeutics targeting Brugia pahangi Hsp90. PLoS Neglected Tropical Diseases 4, e714. doi: 10.1371/journal. pntd.0000714.

Taldone, T., Zatorska, D., Patel, P.D., Zong, H., Rodina, A., Ahn, J. H., Moulick, K., Guzman, M. L. and Chiosis, G. (2011) Design, synthesis, and evaluation of small molecule Hsp90 probes. Bioorganic and Medicinal Chemistry 19, 2603-2614. doi: 10.1016/j.bmc. 2011.03.013.

Tang, Y. T., Gao, X., Rosa, B. A., Abubucker, S., Hallsworth-Pepin, K. Martin, J., Tyagi, R., Heizer, E., Zhang, X., Bhonagiri-Palsikar, V., Minx, P., Warren, W. C., Wang, Q., Zhan, B., Hotez, P. J. 
Sternberg, P. W., Dougall, A., Gaze, S. T., Mulvenna, J., Sotillo, J., Ranganathan, S., Rabelo, E. M., Wilson, R. K., Felgner, P. L., Bethony, J., Hawdon, J.M., Gasser, R.B., Loukas, A. and Mitreva, M. (2014). Genome of the human hookworm Necator americanus. Nature Genetics 46, 261-269. doi: 10.1038/ng.2875.

Tariq, M., Nussbaumer, U., Chen, Y., Beisel, C. and Paro, R. (2009). Trithorax requires Hsp90 for maintenance of active chromatin at sites of gene expression. Proceedings of the National Academy of Sciences USA 106, 1157-1162. doi: 10.1073/pnas.0809669106.

Terhell, A. J., Haarbrink, M., Van Den Biggelaar, A., Mangali, A., Sartono, E. and Yazdanbakhsh, M. (2003). Long-term follow-up of treatment with diethylcarbamazine on anti-filarial IgG4: dosage, compliance, and differential patterns in adults and children. American fournal of Tropical Medicine and Hygiene 68, 33-39.

Thompson, F. J., Cockroft, A.C., Wheatley, I., Britton, C. and Devaney, E. (2001). Heat shock and developmental expression of hsp83 in the filarial nematode Brugia pahangi. European fournal of Biochemistry 268, 5808-5815.

Vercruysse, J., Levecke, B. and Prichard, R. (2012). Human soil-transmitted helminths: implications of mass drug administration. Current Opinion in Infectious Disease 25, 703-708. doi: 10.1097/ QCO.0b013e328358993a.
Walker, G. A., Thompson, F. J., Brawley, A., Scanlon, T. and Devaney, E. (2003). Heat shock factor functions at the convergence of the stress response and developmental pathways in Caenorhabditis elegans. Fournal of the Federation of American Societies for Experimental Biology 17, 1960-1962. doi: 10.1096/fj.03-0164fje.

Wenkert, D., Ramirez, B., Shen, Y. and Kron, M. A. (2010). In vitro activity of geldanamycin derivatives against Schistosoma japonicum and Brugia malayi. Fournal of Parasitology Research 2010, 716498. doi: 10.1155/ 2010/716498.

Wider, D., Peli-Gulli, M.P., Briand, P. A., Tatu, U. and Picard, D. (2009). The complementation of yeast with human or Plasmodium falciparum Hsp90 confers differential inhibitor sensitivities. Molecular and Biochemical Parasitology 164, 147-152.

Wu, C. (1995). Heat shock transcription factors: structure and regulation. Annual Review of Cell Developmental Biology 11, 441-469. doi: 10.1146/ annurev.cb.11.110195.002301.

Xiao, H. and Lis, J. T. (1989). Heat shock and developmental regulation of the Drosophila melanogaster hsp83 gene. Molecular Cell Biology 9, 1746-1753.

Yang, Y., Qin, W., Zarlenga, D., Cao, L. and Tian, G. (2013). TsDAF-21/Hsp90 is expressed in all examined stages of Trichinella spiralis. Veterinary Parasitology 194, 171-174. doi: 10.1016/j.vetpar. 2013.01.048. 